\title{
The role of microRNAs in stemness of cancer stem cells
}

\author{
Seyed Mohammad Ali Hosseini Rad,,2 Mahsa Shanaki Bavarsad, ${ }^{3}$ Ehsan Arefian,, \\ Kaveh Jaseb, ${ }^{3}$ Mohammad Shahjahani, ${ }^{2}$ Najmaldin Saki ${ }^{1,3}$ \\ ${ }^{1}$ Department of Molecular Biology and Genetic Engineering, Stem Cell Technology Research \\ Center, Tehran; ${ }^{2}$ Department of Virology, Faculty of Medical Sciences, Tarbiat Modares University, \\ Tehran; ${ }^{3}$ Health Research Center, Research Institute of Thalassemia and Hemoglobinopathy, \\ Ahvaz Jundishapur University of Medical Sciences, Ahvaz; ${ }^{4}$ Department of Microbiology, \\ School of Biology, College of Science, University of Tehran, Tehran, Iran
}

\begin{abstract}
Cancer is one of the most important diseases of humans, for which no cure has been found so far. Understanding the causes of cancer can pave the way for its treatment. Alteration in genetic elements such as oncogenes and tumor suppressor genes results in cancer. The most recent theory for the origin of cancer has been provided by cancer stem cells (CSCs). Tumor-initiating cells (T-ICs) or CSCs are a small population isolated from tumors and hematologic malignancies. Since CSCs are similar to embryonic stem cells (ESCs) in many aspects (such as pluripotency and self-renewal), recognizing the signaling pathways through which ESCs maintain their stemness can also help identify CSC signaling. One component of these signaling pathways is non-coding RNAs (ncRNAs). ncRNAs are classified in two groups: microRNAs (miRNAs) and long non-coding RNAs (ncRNAs). miRNAs undergo altered expression in cancer. In this regard, they are classified as Onco-miRNAs or tumor suppressor miRNAs. Some miRNAs play similar roles in ESCs and CSCs, such as let-7 and miR-302. This review
\end{abstract}

Correspondence: Najmaldin Saki, Health Research Center, Research Institute of Thalassemia and Hemoglobinopathy, Ahvaz Jundishapur University of Medical Sciences, Ahvaz, Iran.

Tel. +98.6113738317- Fax: +98.6113738330 .

E-mail: najmaldinsaki@gmail.com

Key words: microRNAs, cancer, stemness, cancer stem cells, embryonic stem cells.

Contributions: NS and EA conceived and revised the manuscript. MA, MAHR, $\mathrm{HR}$, MSB, MSh and KJ wrote the manuscript. All authors have given their approval of the final version to be published.

Conflict of interests: the authors declare no conflict of interests.

Acknowledgments: we wish to thank all our colleagues at the Shafa Hospital and the Stem Cell Technology Research Center.

Received for publication: 11 May 2013.

Revision received: 16 September 2013.

Accepted for publication: 7 November 2013.

This work is licensed under a Creative Commons Attribution NonCommercial 3.0 License (CC BY-NC 3.0).

(C) Copyright S.M.A. Hosseini Rad et al., 2013

Licensee PAGEPress, Italy

Oncology Reviews 2013; 7:e8

doi:10.4081/oncol.2013.e8 focuses on the miRNAs involved in stemness of ESCs and CSCs by presenting a summary of the role of miRNAs in other tumor cells.

\section{Introduction}

Cancer stem cells form a small population of cells that are very similar to stem cells within the tumor tissue. One theory is that tumors arise from a small population of cells called tumor-initiating cells (TICs) or cancer stem cells (CSCs). CSCs were first isolated from hematologic malignancies, ${ }^{1}$ and then from solid tumors and breast cancer. ${ }^{2}$ In 1961, it was found that there are cells in tumor tissue capable of producing a variety of tumors. ${ }^{3}$ There are three methods to isolate CSCs: i) isolation using flow cytometry based on Hoechst stain; ii) isolation based on surface marker expression; iii) sphere culture. Prominin-1 $(\mathrm{CD} 133)^{4,5}$ and CD44,7 are two major cell surface markers used to isolate CSCs. These cells must have three properties: tumorigenicity, selfrenewal and pluripotency. ${ }^{8,9}$ Classic treatments for cancer include chemotherapy, radiotherapy and antiangiogenic therapy against proliferating transit-amplifying cells. After a while, due to the presence of therapy-resistant cancer stem cells in tumor tissue, the cancer will appear again. Therefore, treatment should be performed simultaneously against these cells. For this purpose, the differentiation therapy strategy causes differentiation of these cells to proliferating transitamplifying cells sensitive to classic treatments. This strategy, in which targeting of intracellular and extracellular signaling pathways causes disruption of stemness in CSCs, has proved to some extent to be successful. ${ }^{10,11}$

These cells undergo the same signaling pathways as embryonic stem cells (ESCs) such as 0ct-4, Notch, Wnt, Sonic hedgehog (SHH) and Bmi-1. ${ }^{12,13}$ Most of these signaling pathways are involved in selfrenewal of ESCs or tissue adult stem cells and cancer. Mutation and deregulated expression of some components of these signaling pathways has been shown in many human tumors, and hyperactivation of these pathways mostly contribute to tumor regeneration. ${ }^{14-18}$ 0ct- 4 is a core transcriptional regulatory circuitry in $\mathrm{ESCs},{ }^{19}$ and is necessary for reprograming somatic cells into pluripotent state $;^{20}$ it is also known as a pluripotency factor. Pluripotency helps CSCs to maintain an undifferentiated state, supporting the structure of tumor mass. 0ct-4 and its partner Nanog have been shown to be expressed in many human tumors, and their downregulation causes a reduction in CSC stemness and resistance to chemotherapy. ${ }^{21-24}$

Contrary to mRNAs, as their name implies, non-coding RNAs (ncRNAs) do not encode for proteins. They are classified in two groups: those with less than 200 nucleotides (e.g. miRNAs), and those 
with more than 200 nucleotides, such as long non-coding RNAs (lncRNAs) and long intergenic non-coding RNAs (lincRNAs). Meanwhile, it has been shown that p53 activates a lincRNA known as lincRNA-p21, inhibiting the transcription of many genes involved in p53 response. ${ }^{25}$ There is now an increasing trend to identify these IncRNAs and lincRNAs in cancers. ${ }^{26-28}$

MiRNAs are a better-known group of ncRNAs. The first miRNA was discovered in Caenorhabditis elegans. ${ }^{29}$ MiRNAs are non-coding RNAs, 20-25d-nt long, commonly binding the 3' untranslated region (3'UTR) of their targets, inhibiting their translation and regulating their stability. ${ }^{30}$ It has also been shown that some miRNAs can activate gene expression in a specific manner named RNA activatory (RNAa) by targeting regulatory regions (e.g. promoters). ${ }^{31,32}$ MiRNAs, like other genes, undergo altered expression in cancer (oncogenes/tumor suppressor genes). This altered expression is attributed to such mechanisms as chromosomal rearrangements, amplification, mutation and genomic deletion ${ }^{33}$ which are epigenetic mechanisms usually in fragile sites of the genome. ${ }^{34,35}$ The miRNAs are in the form of onco-miR in regions where they are amplified (like miR-17-19 cluster), and are in the form of tumor suppressor miR in the regions where they are deleted, such as miR-15a, 16-1 cluster. The first report on the relationship between miRNAs and cancer was published in 2002. It was found that deletion of a locus on chromosome 13 , which contains miR-15 and miR16-1 in chronic lymphocytic leukemia (CLL), is involved in pathogenesis of the disease. These two miRs bind the anti-apoptotic protein BCL2. In fact, the absence of these miRs inhibits the induction of apoptosis in these cells. ${ }^{34}$

Sometimes, miRNAs have a contradictory role in cancer cells. For example, miR-17-92 locus plays the role of tumor suppressor in human B-cell line by inhibiting proliferation, ${ }^{35}$ and in another cell has an oncomiRNA role along with MYC and inhibition of apoptosis. ${ }^{36}$ Studies have also shown that pri-miRs are involved in cancer independent of their active form (Table 1). ${ }^{37-61}$

\section{MicroRNAs and embryonic stem cells}

Nearly $25 \%$ of the 110,000 known miRNAs are encoded by four clusters: miR-17-92 cluster, miR-21 loci, miR-290-295 cluster and miR-15b16 cluster. The transcription factors Nanog/Oct4/Tcf3 bind the promoter of the miR-302, miR-290/371 cluster, miR-363 cluster, miR-148/152, miR-135b, miR-124, miR-615 and miR-708 clusters in the form of occupancy, and regulate their expression. ${ }^{62,63}$ Core transcriptional regulatory circuitry in ESCs includes Nanog/Oct4/Sox $2,{ }^{19}$ which along with Tcf3 causes the expression of Lin 28 , the latter subsequently inhibiting the processing of let-7. In this regulatory loop, let-7 has a negative effect on the expression of Lin-28. Incoherent feed forward is one of the regulatory mechanisms of miRNAs in ESCs. In fact, we can say that miRNAs are the regulatory arm of transcription factors in expression regulation of downstream genes. ${ }^{64}$ Many studies have been performed on the effect of miRNAs in ESCs. MiR-145 inhibits pluripotency through inhibition of Oct-4, Sox2 and Klf4. ${ }^{65}$ In addition to being able to target 3, UTR in mRNA, miRNAs can target the coding sequence (CDS). MiR296, miR-134 and miR-470 can target CDS regions in 0ct4, Nanog and Sox $2{ }^{66}$

A subset of miR-290 clusters known as regulators of the cell cycle is called embryonic stem cell cycle (ESCC). This subset includes miR-291$3 p$, miR-294 and miR-295. ${ }^{67}$ One theory about the origin of CSCs is reprogramming of somatic cells into dedifferentiation state and CSC formation. When the cells are divided, replication nucleosomes are temporarily removed, and transcription factors can access open chromatin. Therefore, active cell cycle can promote production of induced pluripotency stem cells (iPS). ${ }^{68}$ Some ESCC miRNAs can enhance iPS production by targeting cell cycle inhibitors. hsa-miR-302b and hsamiR-372 promote iPS production by targeting G1-S inhibitors. ${ }^{69}$ In another study, miR-92b promoted G1-S transition by targeting P57KIP2 as CDK inhibitor. ${ }^{70}$

C-Myc is an important factor for reprogramming, especially in its early stages ${ }^{71}$ controlling miRNAs expression by binding to their regulatory regions. It has been shown that c-Myc binds to miR-290-295, ${ }^{72}$ miR-141, miR-200 and miR-429 promoters. ${ }^{73}$ miRNAs profiles are changed during differentiation and reprogramming. Let-7 family, miR210, miR-301, miR-136, miR-145, miR-29a/b, the miR-30 family and some other miRNAs are down-regulated during reprogramming, ${ }^{71,74}$ and some are up-regulated, such as miR-17-92, miR-106b-25 clusters, miR-183 ${ }^{71,74}$ and miR-302 cluster. ${ }^{75}$ Therefore, miRNAs promoting reprogramming and dedifferentiation can be proper candidates for knockdown and differentiation therapy studies. (For more details about the role of miRNAs in stemness and reprogramming, see $\left.e^{52,62,76}\right)$.

\section{MicroRNAs and cancer stem cells}

As mentioned above, reprogramming of differentiated cells into a dedifferentiation state is a stage in CSCs development. Therefore, some mechanisms that take place during reprogramming are involved in tumor development and CSCs formation. Fully differentiated cells undergo epithelial-mesenchymal transition (EMT) by losing adherent molecules (e.g. E-cadherin) and becoming migratory cells. Some factors involved in EMT, such as TGF- $\beta$, Notch1, Wnt, ZEB1/2 and Klf8 induce EMT by repressing E-cadherin expression. ${ }^{77}$ These cells are metastatic, and if they undergo mesenchymal-epithelial transition (MET), they can form CSCs. ${ }^{78}$

A number of miRNAs are involved in EMT as inducers or repressors (Table 2). The most well-known miRNA inhibitor of EMT is the miR-200 family. The miR-200 family and miR-205 inhibit TGF- $\beta$ induced-EMT by targeting ZEB1 and SIP1, and downregulation of these miRNAs is required for induction of EMT in cancer cells. ${ }^{79}$ It is interesting that ZEB1 also blocks the expression of the miR-200 family and miR-141 by binding to their promoters. ${ }^{48} \mathrm{P} 53$ is a repressor of EMT by binding to miR-200c promoter and activating its expression. ${ }^{49}$ It has been shown that miR-200c is down-regulated in breast cancer stem cells..$^{50}$ By inhibiting klf4 transcription factor and polycomb repressor BMI1, miR$200 \mathrm{c}$ inhibits the stemness property of CSCs, the reduced expression of which is observed in breast cancer. ${ }^{50,51}$ As it has previously been observed that p53 induces the differentiation of ESCs by binding to the regulatory region of Nanog gene,${ }^{57}$ it is worth noting that the inhibition of stemness by p53 is also indirectly carried out by activating miRNAs such as miR-200 family members that inhibit BMI1, Sox2, Klf4 and Notch signaling. ${ }^{50,51,58}$ miR-22 indirectly inhibits miR-200 expression and EMT induction in breast cancer by targeting TET and demethylation inhibition of miR-200 promoter. ${ }^{59}$ This study showed that miR-22 plays a role in epigenetic modification and enhances CSCs characteristics. In addition, it has been shown that miR-22 is up-regulated in myelodysplastic syndrome (MDS) and leukemia, and can be considered as a prognostic factor in these patients with low survival. miR-22 targets Methyl cytosine dioxygenase TET2, developing hematopoietic stem cell self-renewal and maintaining stemness. ${ }^{60}$

Another inducer of EMT is the miR-106b-25 cluster, which can promote EMT and CSCs characters in breast cancer model by targeting Smad7 (a negative regulator for TGF- $\beta /$ BMP signaling pathway). ${ }^{61} \mathrm{miR}$ 203 can revert the EMT back to MET by targeting NP63, a predominant p63 isoform and oncogene which promotes CSCs proliferation in breast 
cancer cells. Forced expression of miR-203 caused reduction in CD44 ${ }^{+}$ CD24- CSC population, and increased differentiation to luminal epithelial cells..$^{55,56}$ (For more details about the role of miRNAs in EMT, see $53,54)$.

miR-34a, which is activated by $553{ }^{80}$ directly inhibits CD44 in prostate cancer stem cells; it causes inhibition of metastasis and prevents regeneration of cancer. ${ }^{81}$ In colon CSCs, tumor suppressor miR34 targets Notch1 mRNA to disturb the balance between self-renewal and differentiation in Notch signaling. In this study, it was found that miR-34 determines cell fate in colon CSCs. ${ }^{82}$

miR-9 and miR-9* (miR-9/9*) are expressed in CD133+ glioblastoma stem cells, and promote cell growth and maintain stemness by targeting Calmodulin-binding transcription activator 1 (CAMTA1), which is seen as a tumor suppressor. ${ }^{83}$ Inhibition of miR-9/9* causes glioblastoma stem cell differentiation. ${ }^{84}$ It has been shown that miR-128 inhibits proliferation and self-renewal in glioma CSCs $.^{85} \mathrm{miR}-130 \mathrm{~b}$ promotes stemness and tumorigenicity in $\mathrm{CD}_{133^{+}}$hepatocellular carcinoma (HCC) CSCs through inhibition of Tumor Protein P53 Inducible Nuclear Protein 1 (TP53INP1). Interestingly, forced expression of mir130b in CD133- cells assists in self-renewal activity and chemotherapy resistance. ${ }^{86}$
As mentioned, miR-145 causes differentiation of ESCs by inhibiting the stemness factors. ${ }^{65}$ Interestingly, the expression of miR-145 in prostate and renal cancer cells is inhibited. ${ }^{87,88}$ In addition, miR-21 has been shown to induce stemness in colon cancer cells by modulating TGF $\beta R 2 .{ }^{89}$ Another miRNA down-regulated in CSCs is miR-140. This tumor suppressor miR reduces CSC self-renewal in breast CSCs by targeting Sox9 and ALDH1.$^{90}$ Reduced expression of miR-30 has been shown in CSCs in breast cancer. Increased expression of miR-30 will reduce self-renewal and will increase apoptosis in these cells. ${ }^{91} \mathrm{miR}$ 495 , which up-regulates and targets E-cadherin, contributes to metastasis and DNA damage-inducible transcript 4 (DDIT4) to assist in proliferation and hypoxia resistance in breast CSCs. ${ }^{92}$ (For more details about the role of miRNAs in breast CSCs, see ${ }^{93}$ ).

Altered expression of miR-142-3p, miR-451, miR-106a, miR-249 1425p, miR-15b, miR-20a, miR-106b, miR-25, and miR-486 has been observed in lung cancer progenitor cells. ${ }^{94}$

It has been shown that the expression of miR-302, specific for ES cells, causes the expression of stemness factors such as Nanog, Oct-4 and Sox 2 in cancer cells, conferring a stem cell-like property to them, likely reprogramming these cells to CSCs. ${ }^{95}$ miR-328 helps in drug resistance and metastasis of colon CSCs by targeting ABCG2 and Matrix Metallopeptidase 16. ${ }^{96}$

Table 1. miRNAs involved in cancer.

\begin{tabular}{|c|c|c|c|}
\hline MicroRNAs & Cancer correlation & Function & References \\
\hline miR-15, miR-16 & Induce apoptosis and decrease tumorigenicity, suppress Bcl-2 & TS & 38,39 \\
\hline miR-34a & Induce apoptosis, suppress E2F3, MYCN, CDK4 & TS & $40-42$ \\
\hline miR-143,miR-145 & Down-regulated in cancers & TS & 43 \\
\hline miR-137, miR-193a & Suppress CDK6, E2F & TS & 44 \\
\hline Let-7 & Induce apoptosis and differentiation. Suppress Ras, c-Myc and HMGA2 & TS & $45-47$ \\
\hline miR-21 & Anti-apoptosis, targets Bcl-2, TPM1, PDCD4 & OG & $48-51$ \\
\hline miR-155 & Up-regulated in lymphoma and breast cancer & OG & $52-54$ \\
\hline miR-27 & Targets ZBTB10, RYBP, MYT1 & OG & 55,56 \\
\hline miR-17-19 cluster & Up-regulated in lymphomas and many types of cancers. Targets E2F1, Bim, PTEN and Rb & $\mathrm{TS} / \mathrm{OG}$ & $57-61$ \\
\hline
\end{tabular}

TS, tumor suppressor; OG, oncogene.

Table 2. miRNAs involved in cancer stem cells.

\begin{tabular}{|c|c|c|}
\hline microRNA & Targets & Roles in cancer stem cells \\
\hline miR-200 family & ZEB1 and SIP1, Bmi-1, Klf4 & Inhibition induction of EMT, inhibit BMI1, Sox2, Klf4 and Notch signaling and reduce stemness in CSCs \\
\hline Let-7 & Lin28, H-RAS and HMGA2 & Differentiation of CSCs \\
\hline miR-302 & Genes involved in differentiation & Facilitate dedifferentiation of human tumor cells \\
\hline $\operatorname{miR}-30$ & ITGB3 and Ubc9 & Reduce self-renewal and increases apoptosis \\
\hline miR-140 & Sox9 and ALDH1 & Reduce CSCs self-renewal \\
\hline miR-145 & Oct-4, Sox2 and Klf4 & Inhibit stemness properties \\
\hline miR-128 & Bmi-1 & Disrupting self-renewal of CSCs \\
\hline MiR-34a & CD44 and Notchl & Inhibition of self-renewal \\
\hline miR-203 & $\Delta \mathrm{NP} 63 \alpha$ & Revert EMT to MET and reduction of CSCs population \\
\hline miR-22 & TET & Indirectly repress miR-200 expression and enhance EMT and self-renewal \\
\hline miR-106b-25 & Smad7 & Cause EMT and promote CSCs properties \\
\hline $\operatorname{miR}-9 / 9 *$ & CAMTAl & Maintain stemness property \\
\hline miR-130b & TP53INP1 & Assist self-renewal activity and chemotherapy resistance \\
\hline miR-21 & TGFßR2 & Enhance stemness properties \\
\hline $\operatorname{miR}-495$ & E-cadherin and DDIT4 & Promote metastasis, proliferation and hypoxia resistance of CSCs \\
\hline miR-328 & ABCG2 and MMP16 & Assist metastasis and drug resistance \\
\hline
\end{tabular}

CSCs, cancer stem cells; EMT, epithelial-mesenchymal transition; MET, mesenchymal-epithelial transition. 
Finally, the reduced expression of let-7 has been demonstrated in many cancers. ${ }^{97-99}$ Let-7 inhibits H-RAS and HMGA2. ${ }^{100}$ This factor is controlled by Lin-28; however, methylation of its gene has been observed in lung cancer. ${ }^{101}$ Differentiation of ES cells increases its level; therefore, its expression is expected to decrease in CSCs. As expected, let-7 is significantly decreased in breast CSCs. ${ }^{102}$

\section{Discussion}

Recognizing CSCs as factors of resistance to chemotherapy and recurrence of tumor tissue requires identification of the mechanisms that regulate these cells for therapeutic targets. Since these cells show signaling similar to ESCs and have the two main features of stemness, including pluripotency and self-renewal, they appear to have similarities in expression of stemness factors. Thus, for differentiation therapy purposes, intra- and extracellular mechanisms that maintain this stemness should be further identified. Understanding transcriptome of pluripotency would help find more targets in differentiation therapy of cancer.

Since no specific research has been conducted to identify the miRNAs in various types of CSCs to identify miRNA profiling, we can resort to identifying the miRNAs of ESCs, which are very similar to CSCs. In addition, it has been shown that many of the miRNAs act in nucleus in upregulation of genes by binding to the promoters or antisense transcripts. ${ }^{103}$ Therefore, it would be interesting if such miRNAs that cause upregulation of tumor suppressor genes or differentiation in CSCs can be found. An interesting study using RNAseq technique showed that most of the miRNA are transported to nucleus after maturation in cytoplasm. ${ }^{104}$ The interesting point is that miRNAs that are important in maintaining stemness and differentiation induction in ESCs like mir-145, miR-302 and let7 play similar roles in CSCs. Further studies are required to better understand the role of miRNAs in CSCs. Focusing on this topic can help find new drugs and more effective treatments for cancer. Finally, in line with basic research for finding new targets for treatment, attempts at specific delivery of miRNAs into tumor cells, especially CSCs, should also be approved. Use of active delivery instead of passive delivery by using targeted nanoparticles showed more specificity in drug delivery, and phase /II clinical trials are ongoing. ${ }^{105}$ (For more details about nanoparticle drug delivery, see ${ }^{106}$ ).

\section{References}

1. Lapidot T, Sirard C, Vormoor J, et al. A cell initiating human acute myeloid leukaemia after transplantation into SCID mice. Nature 1994;367:645-8.

2. Al-Hajj M, Wicha MS, Benito-Hernandez A, Morrison SJ, Clarke MF. Prospective identification of tumorigenic breast cancer cells. Proc Natl Acad Sci USA 2003;100:3983-8.

3. Southam CM, Brunschwig A. Quantitative studies of autotransplantation of human cancer. Preliminary report. Cancer 2006;14:971-8.

4. Singh SK, Hawkins C, Clarke ID, et al. Identification of human brain tumour initiating cells. Nature 2004;432:396-401.

5. O'Brien CA, Pollett A, Gallinger S, Dick JE. A human colon cancer cell capable of initiating tumour growth in immunodeficient mice. Nature 2007;445:106-10.

6. Dalerba P, Dylla SJ, Park IK, et al. Phenotypic characterization of human colorectal cancer stem cells. Proc Natl Acad Sci USA 2007;104:10158-63.
7. Patrawala L, Calhoun T, Schneider-Broussard R, et al. Highly purified CD44+ prostate cancer cells from xenograft human tumors are enriched in tumorigenic and metastatic progenitor cells. Oncogene 2006;25:1696-708.

8. Wang JC, Dick JE. Cancer stem cells: lessons from leukemia. Trends Cell Biol 2005;15:494-501.

9. Clarke MF, Dick JE, Dirks PB, et al. Cancer stem cells-perspectives on current status and future directions: AACR Workshop on cancer stem cells. Cancer Res 2006;66:9339-44.

10. Sell S. Leukemia: stem cells, maturation arrest, and differentiation therapy. Stem Cell Rev 2005;1:197-205.

11. Sell S. Stem cell origin of cancer and differentiation therapy. Crit Rev Oncol Hematol 2004;51:1-28.

12. Tai MH, Chang CC, Kiupel M, et al. Oct4 expression in adult human stem cells: evidence in support of the stem cell theory of carcinogenesis. Carcinogenesis 2005;26:495-502.

13. Lobo NA, Shimono Y, Qian D, Clarke MF. The biology of cancer stem cells. Annu Rev Cell Dev Biol 2007;23:675-99.

14. Dontu G, Jackson KW, McNicholas E, et al. Role of Notch signaling in cell-fate determination of human mammary stem/progenitor cells. Breast Cancer Res 2004;6:R605-15.

15. Farnie G, Clarke RB. Mammary stem cells and breast cancer-role of Notch signalling. Stem Cell Rev 2007;3:169-75.

16. Jones DL, Wagers AJ. No place like home: anatomy and function of the stem cell niche. Nat Rev Mol Cell Biol 2008;9:11-21.

17. Klaus A, Birchmeier W. Wnt signalling and its impact on development and cancer. Nat Rev Cancer 2008;8:387-98.

18. Liu S, Dontu G, Mantle ID, et al. Hedgehog signaling and Bmi-1 regulate self-renewal of normal and malignant human mammary stem cells. Cancer Res 2006;66:6063-71.

19. Boyer LA, Lee TI, Cole MF, et al. Core transcriptional regulatory circuitry in human embryonic stem cells. Cell 2005;122:947-56.

20. Buganim Y, Faddah DA, Jaenisch R. Mechanisms and models of somatic cell reprogramming. Nat Rev Genet 2013;14:427-39.

21. Noh KH, Kim BW, Song KH, et al. Nanog signaling in cancer promotes stem-like phenotype and immune evasion. J Clin Invest 2012;122:4077-93.

22. Nagata S, Hirano K, Kanemori M, et al. Self-renewal and pluripotency acquired through somatic reprogramming to human cancer stem cells. PLoS One 2012;7:e48699.

23. Kang J, Shakya A, Tantin D. Stem cells, stress, metabolism and cancer: a drama in two Octs. Trends Biochem Sci 2009;34:491-9.

24. Ibrahim EE, Babaei-Jadidi R, Saadeddin A, et al. Embryonic NANOG activity defines colorectal cancer stem cells and modulates through AP1- and TCF-dependent mechanisms. Stem Cells 2012;30:2076-87.

25. Huarte M, Guttman M, Feldser D, et al. A large intergenic noncoding RNA induced by p53 mediates global gene repression in the p53 response. Cell 2010;142:409-19.

26. Tsai MC, Spitale RC, Chang HY. Long intergenic noncoding RNAs: new links in cancer progression. Cancer Res 2011;71:3-7.

27. Huarte M, Rinn JL. Large non-coding RNAs: missing links in cancer? Hum Mol Genet 2010;19:R152-61.

28. Gibb EA, Brown CJ, Lam WL. The functional role of long non-coding RNA in human carcinomas. Mol Cancer 2011;10:38.

29. Lee RC, Feinbaum RL, Ambros V. The C. elegans heterochronic gene lin-4 encodes small RNAs with antisense complementarity to lin-14. Cell 1993;75:843-54.

30. Rana TM. Illuminating the silence: understanding the structure and function of small RNAs. Nat Rev Mol Cell Biol 2007;8:23-36.

31. Rossi JJ. Transcriptional activation by small RNA duplexes. Nat Chem Biol 2007;3:136-7.

32. Huang V, Place RF, Portnoy V, et al. Upregulation of Cyclin B1 by miRNA and its implications in cancer. Nucleic Acids Res 


\section{2;40:1695-707.}

33. Calin GA, Croce CM. MicroRNA signatures in human cancers. Nat Rev Cancer 2006;6:857-66.

34. Calin GA, Sevignani C, Dumitru CD, et al. Human microRNA genes are frequently located at fragile sites and genomic regions involved in cancers. Proc Natl Acad Sci U S A 2004;101:2999-3004.

35. O'Donnell KA, Wentzel EA, Zeller KI, et al. c-Myc-regulated microRNAs modulate E2F1 expression. Nature 2005;435:839-43.

36. He L, Thomson JM, Hemann MT, et al. A microRNA polycistron as a potential human oncogene. Nature 2005;435:828-33.

37. Jiang J, Lee EJ, Gusev Y, Schmittgen TD. Real-time expression profiling of microRNA precursors in human cancer cell lines. Nucleic Acids Res 2005;33:5394-403.

38. Calin GA, Dumitru CD, Shimizu M, et al. Frequent deletions and down-regulation of micro- RNA genes miR15 and miR16 at 13q14 in chronic lymphocytic leukemia. Proc Natl Acad Sci USA 2002;99:15524-9.

39. Cimmino A, Calin GA, Fabbri M, et al. miR-15 and miR-16 induce apoptosis by targeting BCL2. Proc Natl Acad Sci USA 2005;102:13944-9.

40. Wei JS, Song YK, Durinck S, et al. The MYCN oncogene is a direct target of miR-34a. Oncogene 2008;27:5204-13.

41. Welch C, Chen Y, Stallings RL. MicroRNA-34a functions as a potential tumor suppressor by inducing apoptosis in neuroblastoma cells. Oncogene 2007;26:5017-22.

42. Raver-Shapira N, Marciano E, Meiri E, et al. Transcriptional activation of miR-34a contributes to p53-mediated apoptosis. Molecular Cell 2007;26:731-43.

43. Iorio MV, Ferracin M, Liu CG, et al. MicroRNA gene expression deregulation in human breast cancer. Cancer Res 2005;65:706570 .

44. Kozaki K, Imoto I, Mogi S, et al. Exploration of tumor-suppressive microRNAs silenced by DNA hypermethylation in oral cancer. Cancer Res 2008;68:2094-105.

45. Johnson SM, Grosshans H, Shingara J, et al. RAS is regulated by the let-7 microRNA family. Cell 2005;120:635-47.

46. Lee YS, Dutta A. The tumor suppressor microRNA let-7 represses the HMGA2 oncogene. Genes Dev 2007;21:1025-30.

47. Sampson VB, Rong NH, Han J, et al. MicroRNA let-7a down-regulates MYC and reverts MYC-induced growth in Burkitt lymphoma cells. Cancer Res 2007;67:9762-70.

48. Burk U, Schubert J, Wellner U, et al. A reciprocal repression between ZEB1 and members of the miR-200 family promotes EMT and invasion in cancer cells. ЕMBO Rep 2008;9:582-9.

49. Chang CJ, Chao $\mathrm{CH}$, Xia W, et al. p53 regulates epithelial-mesenchymal transition and stem cell properties through modulating miRNAs. Nat Cell Biol 2011;13:317-23.

50. Shimono Y, Zabala M, Cho RW, et al. Downregulation of miRNA200c links breast cancer stem cells with normal stem cells. Cell 2009;138:592-603.

51. Wellner U, Schubert J, Burk UC, et al. The EMT-activator ZEB1 promotes tumorigenicity by repressing stemness-inhibiting microRNAs. Nat Cell Biol 2009;11:1487-95.

52. Greve TS, Judson RL, Blelloch R. microRNA Control of Mouse and Human Pluripotent Stem Cell Behavior. Annu Rev Cell Dev Biol 2013:29:213-39.

53. Xia H, Hui KM. MicroRNAs involved in regulating epithelial-mesenchymal transition and cancer stem cells as molecular targets for cancer therapeutics. Cancer Gene Ther 2012;19:723-30.

54. Ceppi P, Peter ME. MicroRNAs regulate both epithelial-to-mesenchymal transition and cancer stem cells. Oncogene 2013. [Epub ahead of print].

55. Keyes WM, Pecoraro M, Aranda V, et al. DeltaNp63alpha is an oncogene that targets chromatin remodeler Lsh to drive skin stem cell proliferation and tumorigenesis. Cell Stem Cell 2011;8:164-76.

56. DeCastro AJ, Dunphy KA, Hutchinson J, et al. MiR203 mediates subversion of stem cell properties during mammary epithelial differentiation via repression of DeltaNP63alpha and promotes mesenchymal-to-epithelial transition. Cell Death Dis 2013;4:e514.

57. Lin T, Chao C, Saito S, et al. p53 induces differentiation of mouse embryonic stem cells by suppressing Nanog expression. Nat Cell Biol 2005;7:165-71.

58. Vallejo DM, Caparros E, Dominguez M. Targeting Notch signalling by the conserved miR-8/200 microRNA family in development and cancer cells. EMBO J 2011;30:756-69.

59. Song SJ, Poliseno L, Song MS, et al. MicroRNA-Antagonism Regulates Breast Cancer Stemness and Metastasis via TETFamily-Dependent Chromatin Remodeling. Cell 2013;154:311-24.

60. Song SJ, Ito K, Ala U, et al. The oncogenic microRNA miR-22 targets the TET2 tumor suppressor to promote hematopoietic stem cell self-renewal and transformation. Cell Stem Cell 2013;13:87101.

61. Smith AL, Iwanaga R, Drasin DJ, et al. The miR-106b-25 cluster targets Smad7, activates TGF-beta signaling, and induces EMT and tumor initiating cell characteristics downstream of Sixl in human breast cancer. Oncogene 2012;31:5162-71.

62. Gangaraju VK, Lin H. MicroRNAs: key regulators of stem cells. Nat Rev Mol Cell Biol 2009;10:116-25.

63. Houbaviy HB, Murray MF, Sharp PA. Embryonic stem cell-specific MicroRNAs. Dev Cell 2003;5:351-8.

64. Marson A, Levine SS, Cole MF, et al. Connecting microRNA genes to the core transcriptional regulatory circuitry of embryonic stem cells. Cell 2008;134:521-33.

65. Wang Y, Baskerville S, Shenoy A, Babiarz JE, Baehner L, Blelloch R. Embryonic stem cell-specific microRNAs regulate the G1-S transition and promote rapid proliferation. Nat Genet 2008;40:1478-83.

66. Pekarsky Y, Santanam U, Cimmino A, et al. Tcll expression in chronic lymphocytic leukemia is regulated by miR-29 and miR181. Cancer Res 2006;66:11590-3.

67. Tay Y, Zhang J, Thomson AM, et al. MicroRNAs to Nanog, Oct4 and Sox2 coding regions modulate embryonic stem cell differentiation. Nature 2008;455:1124-8.

68. Vierbuchen T, Wernig M. Molecular roadblocks for cellular reprogramming. Mol Cell 2012;47:827-38.

69. Subramanyam D, Lamouille S, Judson RL, et al. Multiple targets of miR-302 and miR-372 promote reprogramming of human fibroblasts to induced pluripotent stem cells. Nat Biotechnol 2011;29:443-8

70. Sengupta S, Nie J, Wagner RJ, et al. MicroRNA 92b controls the G1/S checkpoint gene p57 in human embryonic stem cells. Stem Cells 2009;27:1524-8.

71. Polo JM, Anderssen E, Walsh RM, et al. A molecular roadmap of reprogramming somatic cells into iPS cells. Cell 2012;151:1617-32.

72. Judson RL, Babiarz JE, Venere M, Blelloch R. Embryonic stem cellspecific microRNAs promote induced pluripotency. Nat Biotechnol 2009;27:459-61.

73. Lin CH, Jackson AL, Guo J, et al. Myc-regulated microRNAs attenuate embryonic stem cell differentiation. EMBO J 2009;28:315770.

74. Chen J, Wang G, Lu C, et al. Synergetic cooperation of microRNAs with transcription factors in iPS cell generation. PLoS One 2012;7:e40849.

75. Wang T, Chen K, Zeng X, et al. The histone demethylases Jhdmla/lb enhance somatic cell reprogramming in a vitamin-Cdependent manner. Cell Stem Cell 2011;9:575-87.

76. Sartipy P, Olsson B, Hyllner J, Synnergren J. Regulation of 'stemness' and stem cell differentiation by microRNAs. IDrugs 2009;12:492-6. 
77. Yang J, Weinberg RA. Epithelial-mesenchymal transition: at the crossroads of development and tumor metastasis. Dev Cell 2008;14:818-29.

78. Kong D, Li Y, Wang Z, Sarkar FH. Cancer Stem Cells and Epithelial-to-Mesenchymal Transition (EMT)-Phenotypic Cells: Are They Cousins or Twins? Cancers (Basel) 2011;3:716-29.

79. Gregory PA, Bert AG, Paterson EL, et al. The miR-200 family and miR-205 regulate epithelial to mesenchymal transition by targeting ZEB1 and SIP1. Nat Cell Biol 2008;10:593-601.

80. Tarasov V, Jung P, Verdoodt B, et al. Differential regulation of microRNAs by $\mathrm{p} 53$ revealed by massively parallel sequencing: miR$34 \mathrm{a}$ is a p53 target that induces apoptosis and G1-arrest. Cell Cycle 2007;6:1586-93.

81. Liu C, Kelnar K, Liu B, et al. The microRNA miR-34a inhibits prostate cancer stem cells and metastasis by directly repressing CD44. Nat Med 2011;17:211-5.

82. Bu P, Chen KY, Chen JH, et al. A microRNA miR-34a-regulated bimodal switch targets notch in colon cancer stem cells. Cell Stem Cell 2013;12:602-15.

83. Barbashina V, Salazar P, Holland EC, Rosenblum MK, Ladanyi M. Allelic losses at 1p36 and 19q13 in gliomas: correlation with histologic classification, definition of a 150 -kb minimal deleted region on 1p36, and evaluation of CAMTA1 as a candidate tumor suppressor gene. Clin Cancer Res 2005;11:1119-28.

84. Schraivogel D, Weinmann L, Beier D, et al. CAMTA1 is a novel tumour suppressor regulated by miR-9/9* in glioblastoma stem cells. EMBO J 2011;30:4309-22.

85. Godlewski J, Nowicki M0, Bronisz A, et al. Targeting of the Bmi-1 oncogene/stem cell renewal factor by microRNA-128 inhibits glioma proliferation and self-renewal. Cancer Res 2008;68:912530.

86. Ma S, Tang KH, Chan YP, et al. miR-130b Promotes CD133(+) liver tumor-initiating cell growth and self-renewal via tumor protein 53-induced nuclear protein 1. Cell Stem Cell 2010;7:694-707.

87. Suh SO, Chen Y, Zaman MS, et al. MicroRNA-145 is regulated by DNA methylation and p53 gene mutation in prostate cancer. Carcinogenesis 2011;32:772-8.

88. Gan B, Lim C, Chu G, et al. FoxOs enforce a progression checkpoint to constrain mTORC1-activated renal tumorigenesis. Cancer Cell 2010;18:472-84.

89. Yu Y, Kanwar SS, Patel BB, et al. MicroRNA-21 induces stemness by downregulating transforming growth factor beta receptor 2 (TGFbetaR2) in colon cancer cells. Carcinogenesis 2012;33:68-76.

90. Li Q, Yao Y, Eades G, et al. Downregulation of miR-140 promotes cancer stem cell formation in basal-like early stage breast cancer. Oncogene 2013. [Epub ahead of print].

91. Yu F, Deng H, Yao H, et al. Mir-30 reduction maintains self-renew- al and inhibits apoptosis in breast tumor-initiating cells. Oncogene 2010;29:4194-204.

92. Hwang-Verslues WW, Chang PH, Wei PC, et al. miR-495 is upregulated by E12/E47 in breast cancer stem cells, and promotes oncogenesis and hypoxia resistance via downregulation of E-cadherin and REDD1. Oncogene 2011;30:2463-74.

93. Schwarzenbacher D, Balic M, Pichler M. The Role of MicroRNAs in Breast Cancer Stem Cells. Int J Mol Sci 2013;14:14712-23.

94. Qian S, Ding JY, Xie R, et al. MicroRNA expression profile of bronchioalveolar stem cells from mouse lung. Biochem Biophys Res Commun 2008;377:668-73.

95. Lin SL, Chang DC, Chang-Lin S, et al. Mir-302 reprograms human skin cancer cells into a pluripotent ES-cell-like state. RNA 2008;14:2115-24.

96. Xu XT, Xu Q, Tong JL, et al. MicroRNA expression profiling identifies miR-328 regulates cancer stem cell-like SP cells in colorectal cancer. Br J Cancer 2012;106:1320-30.

97. Michael MZ, SM OC, van Holst Pellekaan NG, et al. Reduced accumulation of specific microRNAs in colorectal neoplasia. Mol Cancer Res 2003;1:882-91.

98. Takamizawa J, Konishi H, Yanagisawa K, et al. Reduced expression of the let-7 microRNAs in human lung cancers in association with shortened postoperative survival. Cancer Res 2004;64:3753-6.

99. Szafranska AE, Davison TS, John J, et al. MicroRNA expression alterations are linked to tumorigenesis and non-neoplastic processes in pancreatic ductal adenocarcinoma. Oncogene 2007;26:4442-52.

100. Park SM, Shell S, Radjabi AR, et al. Let-7 prevents early cancer progression by suppressing expression of the embryonic gene HMGA2. Cell Cycle 2007;6:2585-90.

101. Brueckner B, Stresemann C, Kuner R, et al. The human let-7a-3 locus contains an epigenetically regulated microRNA gene with oncogenic function. Cancer Res 2007;67:1419-23.

102. Yu F, Yao H, Zhu P, et al. let-7 regulates self renewal and tumorigenicity of breast cancer cells. Cell 2007;131:1109-23.

103. Portnoy V, Huang V, Place RF, Li LC. Small RNA and transcriptional upregulation. Wiley Interdiscip Rev RNA 2011;2:748-60.

104. Liao JY, Ma LM, Guo YH, et al. Deep sequencing of human nuclear and cytoplasmic small RNAs reveals an unexpectedly complex subcellular distribution of miRNAs and tRNA 3' trailers. PLoS One 2010;5:e10563.

105. Davis ME, Chen ZG, Shin DM. Nanoparticle therapeutics: an emerging treatment modality for cancer. Nat Rev Drug Discov 2008;7:771-82.

106. Huang L, Liu Y. In vivo delivery of RNAi with lipid-based nanoparticles. Annu Rev Biomed Eng 2011;13:507-30. 